\title{
Side-effects to Antibiotics in Cystic Fibrosis I: Ocular Changes in Relation to Antibiotic Administration and to Severity of Pulmonary Involvement
}

\author{
C. G. KEITH, JACQUELINE DE HALLER, and WINIFRED F. YOUNG \\ From Queen Elizabeth Hospital for Children, London E.2
}

Blindness occurring in children with cystic fibrosis has been reported by several authors, and it has been suggested that the ocular complications are due to the severity of the disease or to its treatment (Bruce, Denning, and Spalter, 1960; Denning, Bruce, and Spalter, 1963; Spalter and Bruce, 1964; Keith, 1964; Lietman, di Sant' Agnese, and Wong, 1964). This investigation was carried out at the Queen Elizabeth Hospital for Children in an attempt to show the possible causes or predisposing factors.

\section{Subjects and Methods}

Eighty children suffering from this disease were attending regularly for supervision of their treatment, and 42 were chosen for ocular examination, mainly on the grounds of availability and age. Their ages ranged between 2 and 14 years, but the majority were over 5 , when they could co-operate in the examination. (At 14, these patients are usually transferred to an adult hospital.) All the children who had had chloramphenicol were included.

The ocular examination was carried out by one of us (C.G.K.), the findings usually being checked by two assistant ophthalmologists. The ophthalmologist was not aware of the clinical state of the child at the time of examination, having been told only that the child had cystic fibrosis before he filled in a proforma specially set out for use in this investigation. The fundi were examined after mydriasis, the optic discs and retinal vessels were scrutinized, and the relative diameters of the arteries and veins were estimated. Congestion and tortuosity of the veins were recorded when present. All the children were examined between January and June, 1964.

The records of the antibiotic treatment that had been given were usually complete, except for those of a few children who were treated at the start of their illness elsewhere and only came here later. The antibiotics that were used depended on the sensitivity of the organism (usually Staphylococcus pyogenes) found, from pharyngeal swabs or sputum, to be causing infection of

Received November 12, 1965. the lower respiratory tract, and were, therefore, changed from time to time, and the newer antibiotics were used as these became available. In order to treat chronic pulmonary infection, antibiotics were sometimes administered for very long periods. Serial haematological examinations were always carried out in these cases to detect early toxic effects on the bone-marrow.

Cases are grouped according to the radiological severity of their disease. Those in Group I have no evidence of permanent lung damage; those in Group II have minimal localized areas of damage; and those in Group III have multiple areas of shadowing, which persist in serial films.

Groups I and II are subdivided into (a) those without, and (b) those with, a chronic productive cough. The total amounts of antibiotics each child had received and the presence or absence of changes in the fundus are tabulated in Table I. The Groups (Ia, IIa, Ib, IIb, and III) are arranged in order of clinical severity, which is considered to have more serious implications than the radiological grading.

Antibiotics given orally or by injection are tabulated to show the total cumulative amount in grams, and the number of courses for which each had been given, since several short courses may be considered safer than continuous administration. Chlortetracycline, oxytetracycline, and tetracycline are grouped together as tetracyclines, and the sulphonamides were mainly sulphadiazine and sulphathiazole, but a few patients received sulphadimidine and sulphamethoxypyridazine. The daily dose for infants of oral antibiotics, including chloramphenicol, was approximately $100 \mathrm{mg} . / \mathrm{kg}$. body weight given in $\mathbf{4}$ doses, but after infancy the maximum dose was $1 \mathrm{~g}$. daily whatever the size or age of the child. Sulphonamides were given in doses up to $4 \mathrm{~g}$. a day.

Antibiotics given by aerosol are tabulated to show the total amount in grams and the total cumulative duration in weeks for which each had been given. The slight amount absorbed by this route is quite unpredictable, only traces appearing in the urine.

\section{Results}

Only one child (Case 27) had impairment of vision attributable to the disease or its treatment, and details of this case of optic neuritis induced by 
chloramphenicol have already been reported (Keith, 1964). She had received $425 \mathrm{~g}$. chloramphenicol during 15 consecutive months. No signs of toxic retinopathy were found in 18 other children who had had chloramphenicol in amounts varying between 5 and $239 \mathrm{~g}$. ( 3 in excess of $100 \mathrm{~g}$.) in courses of 1 to 16 weeks. In 7 instances, more than one course was given and one child received a total of $239 \mathrm{~g}$. in 32 weeks.

Apart from 4 cases of squint with unilateral amblyopia, all the other children tested had normal vision. 19 showed congestion and tortuosity of the veins of the retina, or an increase above the normal ratio of $3: 2$ of the diameters of comparable veins and arteries (Table I). Among them 1 also had blurring of the margins of the optic discs. Venous congestion was most frequently seen distal to an arteriovenous crossing. The changes were classified as very slight, slight, or definite congestion, depending on the amount of engorgement. The very slight changes may well be within the limits of normal variation, and some normal children are seen with apparently marked venous congestion and tortuosity. However, the findings set out in Table II indicate that these appearances are much more frequent in the groups with severe, than in those with little or no lung disease. Excluding the very slight changes, it can be seen that all but one of the children with slight or definite venous congestion are in Groups IIb and III (Column 4). These children will generally have had more antibiotic treatment than those in other groups, but Table I shows no relation between the antibiotics administered and the degree of vascular engorgement. None of the antibiotics used, apart from chloramphenicol, therefore appear to have caused ocular toxicity.

\section{Discussion}

Bruce et al. (1960) first reported on the ocular changes occurring in cystic fibrosis. They described 24 children who had congestion and tortuosity of the retinal veins, some of whom also had papilloedema, macular oedema, and haemorrhages. In 10, the visual acuity was measured, and it was impaired in 4, 3 of whom had no obvious macular lesion, while one had a macular cyst. A macular hole was found in one other child whose visual acuity had not been tested. Necropsy in 3 children showed retinal oedema and papilloedema.

The authors investigated the relationship of the eye changes to the general condition of the children, i.e. the $\mathrm{CO}_{2}$ reserve, serum proteins, systemic venous pressure, CSF pressure, prothrombin levels, and $p \mathrm{H}$ of the blood. They found that the $\gamma$-globulin levels were raised in all cases but with no excess of macroglobulins. The prothrombin level was reduced in some cases but this was attributed to liver disease. In a later communication, Spalter and Bruce (1964) ascribed the retinopathy to the raised serum $\mathrm{CO}_{2}$ level that occurs in children with severe lung damage. They mentioned the possible relationship of the eye changes to the massive amounts of antibiotic therapy. While none of our series had such severe changes as those described by Bruce et al. (1960), our results show that the venous changes are related to the severity of the lung disease and probably not to any particular antibiotic.

Denning et al. (1963), Keith (1964), and Lietman et al. (1964) have all reported cases of visual failure occurring in children with cystic fibrosis, who received oral chloramphenicol for long periods of time. The cases are summarized in Table III. It can be assumed that all children were receiving adequate vitamin therapy, as this is mandatory in the management of cystic fibrosis. 9 of the 11 reported cases were seen in the acute phase, and 5 showed papillitis, that is a swollen optic disc with venous engorgement and loss of vision, and 2 also had haemorrhages. 2 of the 4 remaining cases showed slight venous engorgement and 2 no fundus abnormality at all, though they later developed optic atrophy. The prognosis was also variable: the vision of 6 children improved to $6 / 12$ or better, though 4 of them had pale optic discs indicating some degree of atrophy, and that of the 5 others did not improve to any significant extent.

There was no definite pattern of response to chloramphenicol. One child recovered normal vision after taking the drug for $\mathbf{4 2}$ months before the onset of symptoms and continued it for 8 months after visual disturbance was noted, and then had further courses of treatment with chloramphenicol; another child developed irreversible visual loss after only $4 \frac{1}{2}$ months of treatment, the drug having been stopped immediately the visual symptoms were noticed. The pathological changes that occur after optic neuritis due to chloramphenicol toxicity were described by Wong and Collins (1965) in 2 children who succumbed to cystic fibrosis. They found loss of the ganglion cells in the retina and demyelination in the optic nerve. All the other layers of the retina were normal, indicating either a selective action on the ganglion cells with consequent atrophy of their axons running in the optic nerve, or a primary effect on the axons with secondary degeneration of the ganglion cells. The toxic agent might even affect the retina and nerve simultaneously, and at present it is impossible to say which is the primary event. Clinically, the term optic neuritis is used to describe 


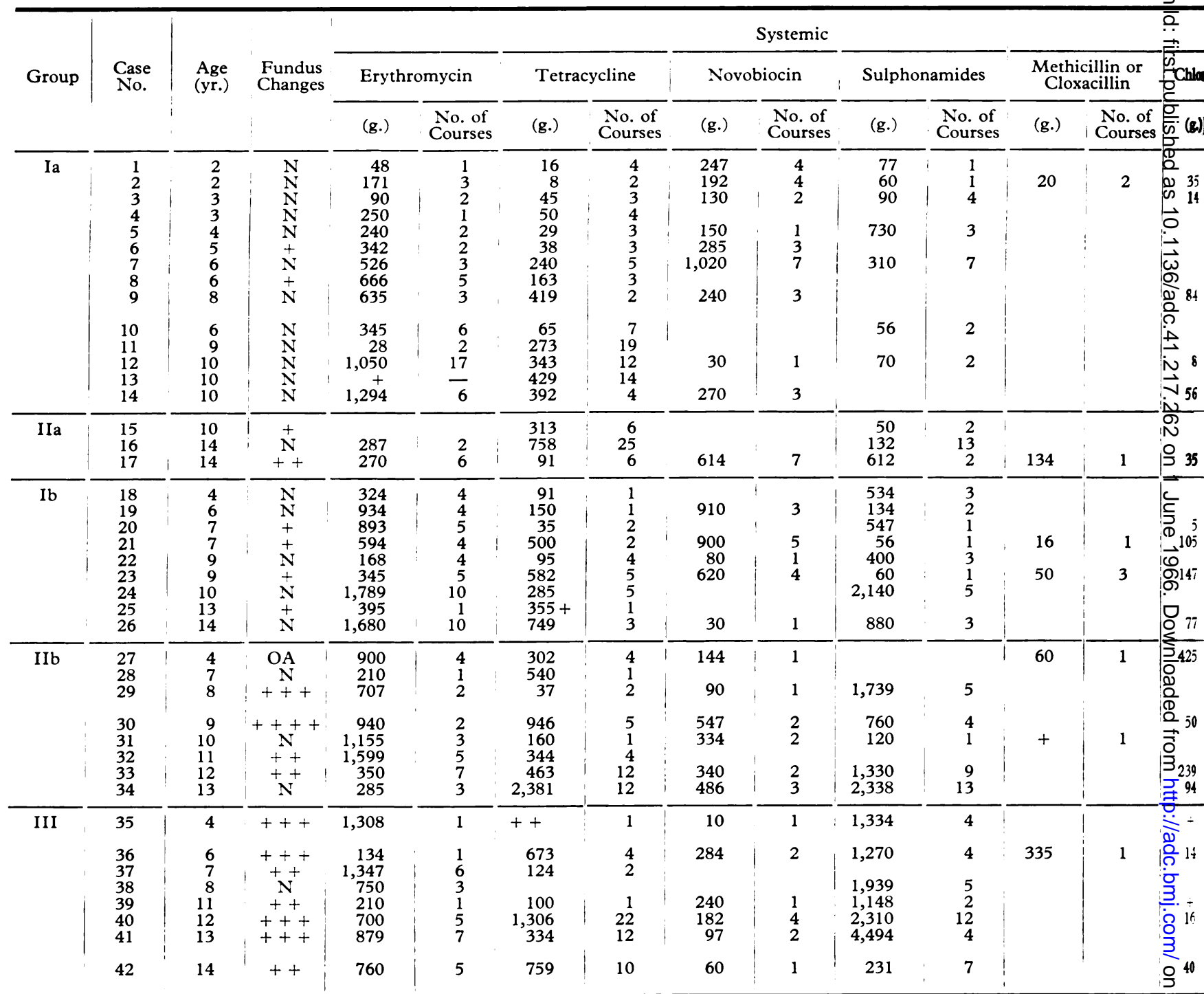

$\star \mathrm{P}=$ penicillin $\mathrm{S}=$ streptomycin $\mathrm{O}=$ oleandomycin $\mathrm{C}=$ cloxacillin $; \mathrm{CS}=$ colistin sulphate $; \mathrm{PB}=$ polymixin $\mathrm{B}$

Examination of Fundus: $\mathrm{N}=$ normal; $+=$ very slight congestion of veins distal to arteriovenous crossings, or a vein to artery size ratio 2

of the disc margin. $\mathrm{OA}=$ optic atrophy.
Antibiotics: Systemic penicillin and streptomycin are indicated as + , if given for $<1$ month; ++ , if given for $<3$ months; and +++ , if ${ }^{2}$ iven

TABLE II

Incidence of Eye Changes According to Clinical Severity

\begin{tabular}{c|c|c|c}
\hline Group & No. of Cases & $\begin{array}{c}\text { No. with } \\
\text { Eye Changes }\end{array}$ & $\begin{array}{c}\text { No. with } \\
\text { Significant } \\
\text { Changes }^{\star}\end{array}$ \\
\hline Ia & 14 & 2 & 0 \\
IIa & 3 & 2 & 1 \\
Ib & 9 & 4 & 0 \\
IIb & 8 & 4 & 4 \\
III & 8 & 7 & 7
\end{tabular}

$\star$ Cases with only minor degrees of venous engorgement have been omitted. any of these events, unless the retinopathy is obvious as in chloroquine toxicity.

Unfortunately, the fundus appearances may be similar in the retinopathy related to the severity of the disease and that due to optic neuritis caused by chloramphenicol toxicity. The main differentiating feature between papilloedema and optic neuritis is the degree of visual acuity, which may be difficult or impossible to obtain in young children. Any suspected loss of vision in these children should, therefore, be thoroughly investigated for a possible cause of toxicity, especially chloramphenicol. Since 
TABLE III

Published Cases of Cystic Fibrosis with Optic Neuritis due to Chloramphenicol

\begin{tabular}{|c|c|c|c|c|c|c|c|c|c|c|}
\hline & \multirow{3}{*}{ Case } & \multirow{3}{*}{$\begin{array}{l}\text { Age } \\
\text { (yr.) }\end{array}$} & \multicolumn{3}{|c|}{ Chloramphenicol } & \multicolumn{2}{|r|}{ Initial } & \multirow{3}{*}{$\begin{array}{c}\text { Course } \\
\text { of } \\
\text { Condition }\end{array}$} & \multirow{3}{*}{\multicolumn{2}{|c|}{$\mid \begin{array}{l}\text { Final } \\
y\end{array}$}} \\
\hline & & & \multicolumn{2}{|c|}{ Months } & \multirow{2}{*}{$\begin{array}{l}\text { Dose } \\
\text { (mg.) } \\
\text { kg. }\end{array}$} & \multirow{2}{*}{$\begin{array}{l}\text { Visual } \\
\text { Acuity }\end{array}$} & \multirow[b]{2}{*}{ Fundus } & & & \\
\hline & & & $\begin{array}{c}\text { Before } \\
\text { Symp- } \\
\text { toms }\end{array}$ & $\begin{array}{c}\text { After } \\
\text { Symp- } \\
\text { toms }\end{array}$ & & & & & & \\
\hline Denning et al. (1963) & $\begin{array}{l}1 \\
2 \\
3 \\
4\end{array}$ & $\begin{array}{r}6 \\
10 \\
8 \\
11\end{array}$ & $\begin{array}{l}42 \\
12 \\
30 \\
48\end{array}$ & $\begin{array}{l}8 \\
2 \\
? \\
3+\end{array}$ & $\begin{array}{l}50 \\
50 \\
50 \\
50\end{array}$ & $\begin{array}{l}3 / 60 \\
6 / 60 \\
1 / 60 \\
6 / 36\end{array}$ & $\begin{array}{l}\text { Pale discs } 8 \text { mth. after } \\
\text { symptoms started } \\
\text { Papilloedema } \\
\text { Papilloedema with } \\
\text { haemorrhages } \\
\text { Blurred disc margins } \\
\text { with tortuous veins } \\
\text { ( } 3 \text { mth. after onset) }\end{array}$ & $\begin{array}{l}\text { Improved } \\
\text { Not } \\
\text { improved } \\
\text { Improved } \\
\text { Not } \\
\text { improved }\end{array}$ & $\begin{array}{l}6 / 6 \\
- \\
6 / 12 \\
-\end{array}$ & $\begin{array}{l}\text { Optic atrophy } \\
\text { Optic atrophy } \\
\text { Optic atrophy } \\
\text { Pale discs }\end{array}$ \\
\hline Lietman et al. (1964) & $\begin{array}{l}5 \\
6 \\
7 \\
8 \\
9 \\
10\end{array}$ & $\begin{array}{r}2 \cdot 10 \\
4 \cdot 9 \\
5 \cdot 9 \\
6 \\
6 \cdot 8 \\
6 \cdot 9\end{array}$ & $\begin{array}{c}24 \\
4 \frac{1}{2} \\
8 \\
9 \\
8 \\
3 \frac{1}{2}\end{array}$ & $\begin{array}{c}0 \\
0 \\
1 \\
1 \frac{1}{2} \\
\text { Not } \\
\text { stop- } \\
\text { ped } \\
2\end{array}$ & $\begin{array}{l}40 \\
59 \\
40 \\
41 \\
54 \\
5\end{array}$ & $\begin{array}{c}- \\
6 / 60 \\
6 / 18 \\
1 / 60 \\
?\end{array}$ & $\begin{array}{l}\text { - } \\
\text { Discs blurred and pale, } \\
\text { tortuous vessels } \\
\text { Slight venous engorge- } \\
\text { ment } \\
\text { Vision full; pigment at } \\
\text { macula } \\
\text { Papilloedema with } \\
\text { haemorrhages }\end{array}$ & $\begin{array}{l}\text { Improved } \\
\text { Not } \\
\text { improved } \\
\text { Improved } \\
\text { Improved } \\
\text { Not } \\
\text { improved } \\
\text { Improved }\end{array}$ & \begin{tabular}{|c|}
$6 / 9$ \\
$6 / 6$ \\
- \\
Counting \\
fingers \\
$6 / 9$
\end{tabular} & $\begin{array}{l}\text { Normal } \\
\text { Optic atrophy } \\
\text { Optic atrophy } \\
\text { Normal } \\
\text { Macular pig- } \\
\text { mentation; } \\
\text { pale discs } \\
\text { Pale discs }\end{array}$ \\
\hline Keith (1964) .. & 11 & 4 & 9 & 6 & 50 & $1 / 60$ & Normal & Not & $1 / 60$ & Optic atrophy \\
\hline
\end{tabular}

degree of engorgement of the retinal veins, and this was related to the severity of their lung disease but not to antibiotic administration.

Very large amounts of the tetracyclines, sulphonamides, erythromycin, and novobiocin were found to have had no ocular side-effects in this series of patients.

Of the 19 children who had received chloramphenicol, 1 developed optic neuritis following administration of the drug for 69 weeks, and this caused permanent loss of vision. The others were not affected after receiving it in full dosage for 1 to 32 weeks.

The published material on the ocular manifestations of cystic fibrosis, and of chloramphenicol toxicity occurring in this disease, is reviewed, and the importance of using visual acuity to differentiate between optic neuritis and papilloedema is stressed.

Chloramphenicol should probably not be given for periods of longer than one month, as optic neuritis has occurred after as little as $3 \frac{1}{2}$ months of treatment, but its use for short periods seems to carry no ocular danger. Long-term chlorampheni- col treatment is seldom required to control pulmonary infection in children with cystic fibrosis now that a wider range of antibiotics is available.

We wish to express our gratitude to the consultant medical staff of the hospital for referring the cases to us, and to Dr. M. Mearns and Miss V. Ambridge for their help in collecting the data and to Miss A. Playfoot for secretarial assistance.

\section{REFERENCES}

Bruce, G. M., Denning, C. R., and Spalter, H. F. (1960). Ocular findings in cystic fibrosis of the pancreas: a preliminary report. A.M.A. Arch. Ophthal., 63, 391.

Denning, C. R., Bruce, G. M., and Spalter, H. F. (1963). Optic neuritis in chloramphenicol-treated patients with cystic fibrosis. Presented at the Fourth Annual Meeting of the Cystic Fibrosis Club.

Keith, C. G. (1964). Optic atrophy induced by chloramphenicol. Brit. F. Ophthal., 48, 567.

Lietman, P. S., di Sant' Agnese, P. A., and Wong, V. (1964). Optic neuritis in cystic fibrosis of the pancreas. Role of chloramphenicol therapy. f. Amer. med. Ass., 189, 924.

Sloan, P. G. (1962). Ocular side effects of systemic medication. Amer. F. Optom., 39, 459.

Spalter, H. F., and Bruce, G. M. (1964). Ocular changes in pulmonary insufficiency. Trans. Amer. Acad. Ophthal. Otolaryng., 68, 661.

Wong, V. G., and Collins, E. (1965). Optic atrophy in cystic fibrosis of the pancreas. Amer. F. Ophthal., 59, 763. 